\title{
Surgical management of the functional mitral regurgitation in heart failure patients
}

\author{
Starck, Christoph Thomas ; Schönrath, Felix ; Scherman, Jacques ; Caliskan, Etem ; Falk, Volkmar
}

\begin{abstract}
Relevant secondary mitral regurgitation occurs in $35-50 \%$ of patients with chronic heart failure and is associated with increased mortality. Surgical management of patients with mitral valve regurgitation and heart failure remains controversial. There are several questions which are not sufficiently clarified because of a lack of prospective randomised controlled trials: (1.) The indication for concomitant mitral valve surgery in patients undergoing coronary artery bypass grafting (CABG) with moderate to severe mitral valve regurgitation; (2.) the management of functional mitral valve regurgitation; (3.) the appropriate surgical strategy: repair or chordal-sparing replacement.
\end{abstract}

Posted at the Zurich Open Repository and Archive, University of Zurich

ZORA URL: https://doi.org/10.5167/uzh-90126

Journal Article

Published Version

Originally published at:

Starck, Christoph Thomas; Schönrath, Felix; Scherman, Jacques; Caliskan, Etem; Falk, Volkmar (2013). Surgical management of the functional mitral regurgitation in heart failure patients. Cardiovascular Medicine, 16(3):82-86. 


\title{
Surgical management of functional mitral regurgitation in heart failure patients
}

\author{
Christoph T. Starck, Felix Schönrath, Jacques Scherman, Etem Caliskan, Volkmar Falk
}

Clinic of Cardiac and Vascular Surgery, University Hospital Zurich, Switzerland

\section{Summary}

Relevant secondary mitral regurgitation occurs in 35$50 \%$ of patients with chronic heart failure and is associated with increased mortality.

Surgical management of patients with mitral valve regurgitation and heart failure remains controversial. There are several questions which are not sufficiently clarified because of a lack of prospective randomised controlled trials: (1.) The indication for concomitant mitral valve surgery in patients undergoing coronary artery bypass grafting (CABG) with moderate to severe mitral valve regurgitation; (2.) the management of functional mitral valve regurgitation; (3.) the appropriate surgical strategy: repair or chordal-sparing replacement.

Key words: mitral valve surgery; heart failure; functional mitral regurgitation; ischaemic mitral regurgitation

\section{Pathophysiology of functional mitral regurgitation in heart failure}

Primary organic mitral valve regurgitation and secondary, functional mitral regurgitation (MR) are two different entities. The former is a valvular disease whereas the latter is a ventricular disease. Functional MR in patients with severe left ventricular dysfunction is a consequence of distorted left ventricular geometry $[4,5]$. Basically, functional MR can be caused by two different ventricular pathologies: ischaemic cardiomyopathy and idiopathic dilated cardiomyopathy. In both diseases, changes in left ventricular geometry and left ventricular dilatation lead to a displacement of one or both papillary muscles. This mechanism pulls the leaflets into the left ventricle (tethering), which results in tenting of the valve below the plane of the annulus. Tethering of the mitral leaflets leads to a reduced area of leaflet coaptation (fig. 1). It has been reported that functional MR, in addition, results

Funding / potential competing interests: No financial support and no other potential conflict of interest relevant to this article was reported. in a dilated and deformed mitral annulus, although the leaflets are usually morphologically normal [6]. It has been shown recently that the leaflets of the valve may also suffer from this pathology and un-
Figure 1

Pathophysiology of functional mitral regurgitation. Changes in left ventricular geometry and left ventricular dilatation lead to a displacement of one or both papillary muscles. This mechanism pulls the mitral leaflets into the left ventricle (tethering). The triangle represents the tenting area (area enclosed between the annular plane and the mitral leaflets). ( $\mathrm{AML}=$ anterior mitral leaflet; $\mathrm{PML}=$ posterior mitral leaflet; $\mathrm{a}=$ anterior mitral leaflet angle; $\mathrm{b}=$ posterior mitral leaflet angle; $d=$ coaptation depth).

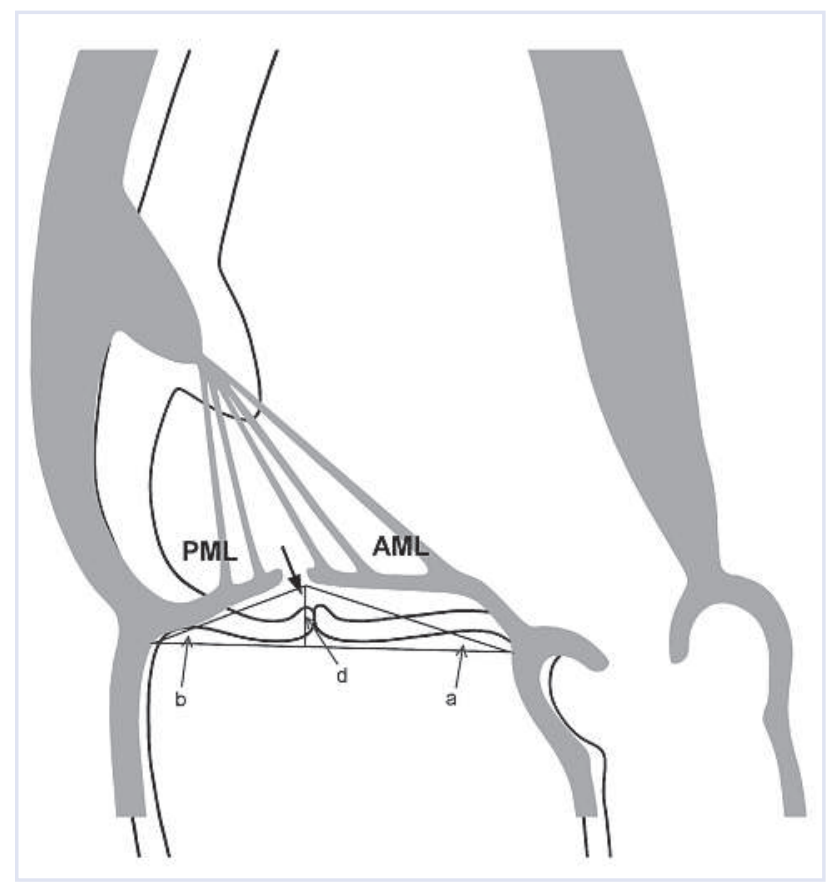

dergo visible histological and anatomical remodelling: The chords become stiffer and restrictive, and the leaflets become stiffer, more stretched and thicker [5]. Several authors have demonstrated that MR induces further left ventricular dilatation through neurohu-

Correspondence:

Christoph T. Starck, MD

Clinic of Cardiac and Vascular Surgery

University Hospital Zurich

Raemistrasse 100

CH-8091 Zurich

Switzerland

christophthomas.starck[at]usz.ch 
moral and cytokine activation [7-9]. Therefore, in patients with heart failure and significant functional MR a vicious cycle evolves, which eventually leads to terminal cardiac failure if the remodelling of the ventricle or MR is not reversed [10-12].

\section{Surgical management}

The basic principle of the surgical treatment of functional MR is to restore coaptation of the mitral leaflets by reshaping the mitral annulus with reduction of the septolateral distance, so that the anterior mitral leaflet covers the complete orifice of the mitral valve [5]. This is achieved by means of a restrictive, undersized annuloplasty (fig. 2). An annuloplasty ring is implanted that is at least two sizes smaller than the ring that would have been chosen on the basis of measuring the intertrigonal distance and the surface of the anterior leaflet as a reference [13].

With regard to the annuloplasty ring used for the treatment of functional MR, Spoor et al. and Silbermann et $a l$. were able to show that complete and rigid annuloplasty rings ensure better outcomes than partial and flexible rings $[14,15]$.

Further surgical techniques for repair of functional MR include anterior leaflet augmentation with a pericardial patch when the anterior leaflet length is less than $25 \mathrm{~mm}$, in order to increase the coaptation area [16, 17], or the addition of the edge-to-edge technique to the annuloplasty [18]. In the case of increased tethering of second-order chords of the anterior leaflet, mobility of the leaflet can be increased by cutting these secondorder chords [5].

In patients where successful and durable repair is questionable or who show no potential for reverse remodelling, chordal-sparing mitral valve replacement is a good alternative. Several studies showed no longterm mortality difference in patients with ischaemic MR undergoing mitral valve replacement rather than mitral valve repair [19-21]. The exact role of mitral valve replacement in comparison to mitral valve re-

\section{Figure 2}

Schematic illustration of the restrictive annuloplasty technique.

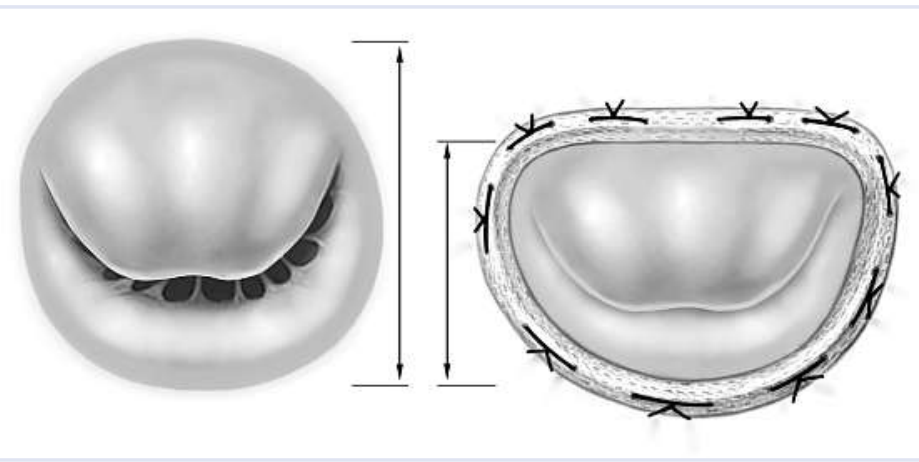

pair, especially restrictive annuloplasty, in functional MR has, however, not been clarified because of the lack of results of prospective randomised trials. A randomised clinical trial is currently being performed by the Cardiothoracic Surgical Trials Network in order to answer this question. In this study patients with severe MR secondary to chronic ischaemic cardiomyopathy are randomised to either mitral valve replacement or mitral valve repair.

Predictors of unsuccessful or not durable mitral valve repair after restrictive annuloplasty have been defined and are summarised in table 1 [13]. These predictors may be helpful for planning surgery, especially with regard to the question of whether to perform a repair or a valve replacement in the first instance.

\section{Results of mitral valve surgery in patients with functional mitral regurgitation and heart failure}

It is hard to draw concrete conclusions from data with regard to mitral valve surgery for functional MR in heart failure patients since only a few prospective randomised trials exist and most evidence is based upon retrospective and observational studies.

Mitral valve surgery for functional MR can be achieved with low operative mortality (1.6-5\%) and different studies have shown that it leads to symptomatic improvement and a better quality of life [1, 22-24]. Furthermore, several authors showed that successful surgical treatment of functional MR has the potential to lead to reverse remodelling of the diseased left ventricle [24-26]. Despite obvious improvements in symptomatology, the prognostic value of mitral valve surgery in heart failure patients remains unclear. Wu et al. retrospectively analysed consecutive patients with significant MR and left ventricular systolic dysfunction who were treated at the University of Michigan between 1995 and 2002. A total of 682 patients were identified and divided into two groups according to their therapy, either mitral valve annuloplasty or medical therapy. They were able to show that there is no survival benefit with mitral valve annuloplasty [27].

One difficult aspect of mitral valve repair in patients with functional MR is the problem of recurrence rates of up to $30 \%$ in the initial years after surgery, which again negatively affects the course of heart failure and survival in these patients $[1,12,28,29]$. With this in mind, the lack of survival benefit with mitral valve annuloplasty for functional MR in heart failure patients might be related to the less durable relief of MR with mitral valve annuloplasty [1]. Therefore, chordal-sparing mitral valve replacement might show a mortality benefit owing to its durable relief of MR, and it should certainly not be regarded as surgical failure. This issue needs to be investigated in future randomised prospective trials in order to identify the best surgical treatment for these patients. 
Best outcomes with regard to reverse ventricular remodelling after restrictive annuloplasty were achieved in patients with small preoperative left ventricular size (left ventricular end-diastolic diameter (LVEDD) less than $65 \mathrm{~mm}$ ) [24, 25]. The potential for reverse remodelling is an important aspect to consider when recommending mitral surgery in heart failure patients. Besides the absence of severe ventricular dilatation, there are other predictors for favourable reverse remodelling including a lower sphericity index and the presence of left ventricular contractile reserve [1]. The degree of contractile reserve in particular is a predictor of left ventricular function after mitral valve repair in heart failure patients and should be included in the preoperative assessment [30, 31].

It is important to mention that an individualised approach to such patients is essential for good outcomes. In particular, patients with predictors for less durable or unsuccessful mitral valve repair (table 1) should be identified and because chordal sparing mitral valve replacement might sometimes be the better approach for such patients.

Table 1

Predictors of recurrent mitral regurgitation after restrictive annuloplasty in patients with functional mitral regurgitation.

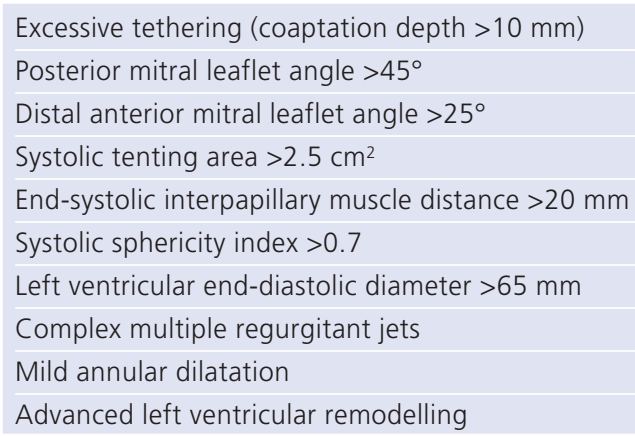

With regard to the underlying ventricular disease, two different groups can be identified: patients with MR due to ischaemic or idiopathic dilated cardiomyopathy. The treatment of heart failure patients with ischaemic MR is especially controversial.

\section{Results of surgery for functional mitral regurgita- tion in patients with ischaemic cardiomyopathy}

In an observational study in patients with moderate to severe functional ischemic MR, Mihaljevic et al. examined the benefit of adding mitral valve annuloplasty (MVA) to a coronary artery bypass graft (CABG) procedure, compared with merely performing CABG surgery. Based on their results in 390 patients with a median follow-up of four years (CABG and MVA) and five years (CABG alone), they concluded that the addition of mitral valve annuloplasty to CABG surgery did not improve long-term functional status or survival compared with CABG alone [32].
In contrast Deja et al. reported a benefit with regard to early and long-term survival from adding mitral valve annuloplasty to CABG surgery, as compared with CABG or medical therapy alone. They performed a survival analysis of 1,212 patients enrolled in the Surgical Treatment for Ischaemic Heart Failure (STICH) trial to investigate the impact of adding mitral valve repair in a subset of patients with moderate to severe chronic ischemic MR prospectively randomised, in accordance with the study design, to receive CABG or optimised medical therapy [33, 34].

\section{Results of surgery for functional mitral regurgi- tation in patients with dilated cardiomyopathy}

With regard to surgical therapy of functional MR in patients with dilated cardiomyopathy, Acker et al. published results from 193 patients prospectively randomised to mitral valve repair alone or mitral repair plus implantation of a left ventricular passive restraint device (CorCap, Acorn Cardiovascular, USA). They reported a low 30 -day mortality of $1.6 \%$ and survival rates of $86.5 \%$ and $85.2 \%$, respectively, at 1 and 2 years after surgery. They were able to show significant evidence of reverse remodelling and symptomatic benefit after mitral valve repair [35]. DeBonis et al. also proved the benefit of mitral valve repair in heart failure patients with functional MR and end-stage dilated cardiomyopathy. They were able to show a significant improvement in New York Heart Association (NYHA) functional class. In patients with a coaptation depth of more than $10 \mathrm{~mm}$ they added the edge-to-edge technique to a restrictive annuloplasty and found a lower recurrence rate of significant MR than in the patients with restrictive annuloplasty alone (3.7\% vs $21.7 \%$ ) [18].

\section{Indications for surgery of functional mitral regurgitation (ESC Guidelines)}

The therapy of functional MR in heart failure patients is addressed in the European Society of Cardiology (ESC) guidelines on the management of valvular heart disease and the ESC heart failure guidelines, both published in 2012.

In patients with severe MR undergoing CABG surgery, the addition of mitral repair is a class I indication in patients with a left ventricular ejection fraction (LVEF) of more than $30 \%$ and a class IIa indication in patients with a LVEF of less than $30 \%$. In patients with moderate MR for whom CABG surgery is planned, mitral valve repair is a class IIa indication. In patients with severe MR, a LVEF of more than $30 \%$ and no option for revascularisation, mitral valve repair represents a class IIb indication in the presence of persisting symptoms despite optimal medical management (including cardiac resynchronisation therapy (CRT) if indicated) and low comorbidity. 
In patients with severe functional MR and severely depressed LVEF, who cannot be revascularised or who present with nonischaemic cardiomyopathy, the guidelines recommend isolated mitral valve surgery only in selected patients with low comorbidity in order to avoid or postpone transplantation. In most other such patients, conventional medical therapy is recommended as the first line, followed, in the event of failure of extended heart failure treatment (CRT, ventricular assist devices, cardiac restraint devices, heart transplantation).

As an alternative to mitral valve surgery, the percutaneous edge-to-edge repair may be considered (class IIb indication) in patients with symptomatic severe functional MR despite optimal medical therapy, including CRT if indicated, who are considered eligible after echocardiography, and are judged inoperable or at high operative risk by a team of cardiologists and cardiac surgeons [36, 37].

A decision algorithm for the treatment of functional mitral regurgitation in heart failure patients with severely depressed LVEF, based on the ESC guidelines, is displayed in figure 3 .

\section{Figure 3}

Decision algorithm for the treatment of functional mitral regurgitation in heart failure patients with severely depressed LVEF based on the ESC guidelines.

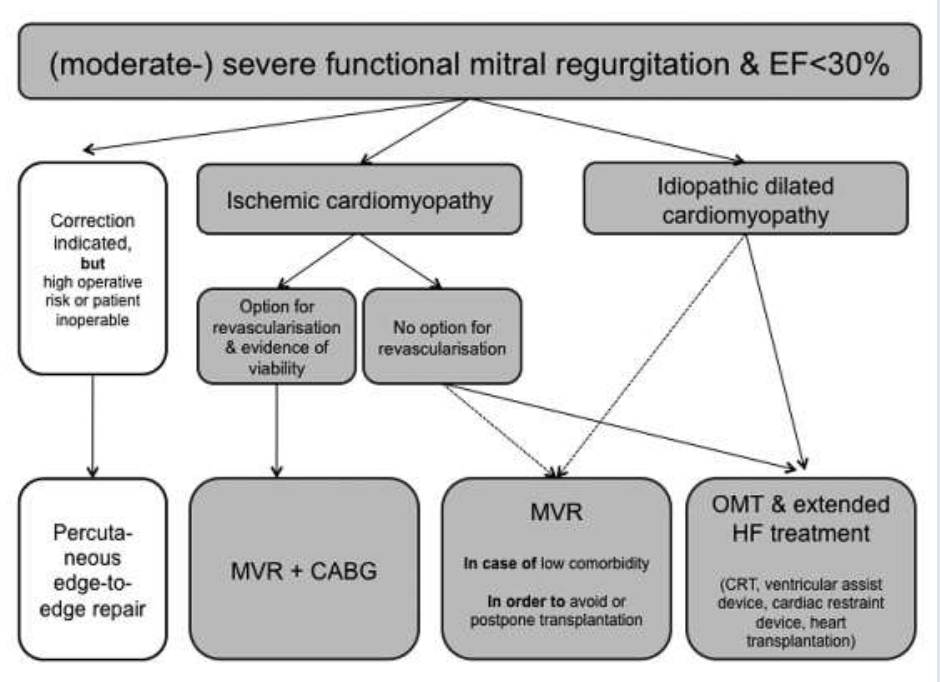

\section{Conclusion}

Surgical treatment of patients with significant functional MR and left ventricular dysfunction cannot be generalised and is nowadays characterised by a persisting lack of evidence. Optimal treatment of these severely sick patients needs to be individualised on the basis of the underlying pathology. In addition to optimised medical therapy and CRT, if appropriate, surgery is an important part of the treatment of such pa- tients, since, in experienced centres, it can be achieved with low operative mortality and postoperative symptomatic benefit.

\section{References}

1 Di Salvo TG, Acker MA, Dec GW, Byrne JG. Mitral valve surgery in advanced heart failure. J Am Coll Cardiol. 2010;55:271-82.

2 Mehra MR, Reyes P, Benitez RM, Zimrin D, Gammie JS. Surgery for severe mitral regurgitation and left ventricular failure: what do we really know? J Card Fail. 2008;14:145-50.

3 Trichon BH, Felker GM, Shaw LK, Cabell CH, O'Connor CM. Relation of frequency and severity of mitral regurgitation to survival among patients with left ventricular systolic dysfunction and heart failure. Am J Cardiol. 2003;91:538-43.

4 Carabello BA. The current therapy for mitral regurgitation. J Am Coll Cardiol. 2008;52:319-26.

5 Calafiore AM, Iacò AL, Tash A, Abukudair W, Di Mauro M. Mitral valve surgery for functional mitral regurgitation in patients with chronic heart failure - update of the results. Thorac Cardiovasc Surg. 2010;58: $131-5$.

6 Hueb AC, Jatene FB, Moreira LF, Pomerantzeff PM, Kallás E, de Oliveira SA. Ventricular remodeling and mitral valve modifications in dilated cardiomyopathy: new insights from anatomic study. J Thorac Cardiovasc Surg. 2002;124:1216-24.

7 Dell'Italia LJ, Meng QC, Balcells E, Straeter-Knowlen IM, Hankes GH, Dillon R, et al. Increased ACE and chymase-like activity in cardiac tissue of dogs with chronic mitral regurgitation. Am J Physiol. 1995;269: H2065-H2073.

8 Kapadia SR, Yakoob K, Nader S, Thomas JD, Mann DL, Griffin BP. Elevated circulating levels of serum tumor necrosis factor-alpha in patients with hemodynamically significant pressure and volume overload. J Am Coll Cardiol. 2000;36:208-12.

9 Talwar S, Squire IB, Davies JE, Ng LL. The effect of valvular regurgitation on plasma cardiotrophin-1 in patients with normal left ventricular systolic function. Eur J Heart Fail. 2000;2:387-91.

10 Otsuji Y, Handschumacher MD, Liel-Cohen N, Tanabe H, Jiang L, Schwammenthal E, et al. Mechanism of ischemic mitral regurgitation with segmental left ventricular dysfunction: three-dimensional echocardiographic studies in models of acute and chronic progressive regurgitation. J AmColl Cardiol. 2001;37:641-8.

11 Liel-Cohen N, Guerrero JL, Otsuji Y, Handschumacher MD, Rudski LG, Hunziker PR, et al. Design of a new surgical approach for ventricular remodeling to relieve ischemic mitral regurgitation. Circulation. 2000; 101:2756-63.

12 Hung J, Papakostas L, Tahta SA, Hardy BG, Bollen BA, Duran CM, et al. Mechanism of recurrent ischemic mitral regurgitation post-annuloplasty: continued LV remodeling as a moving target. Circulation. 2004; 110:85-90.

13 De Bonis M, Maisano F, La Canna G, Alfieri O. Treatment and management of mitral regurgitation. Nat Rev Cardiol. 2011;9:133-46.

14 Spoor MT, Geltz A, Bolling SF. Flexible versus nonflexible mitral valve rings for congestive heart failure: differential durability of repair. Circulation. 2006;114:I67-I71.

15 Silberman S, Klutstein MW, Sabag T, Oren A, Fink D, Merin O, et al. Repair of ischemic mitral regurgitation: comparison between flexible and rigid annuloplasty rings. Ann Thorac Surg. 2009;87:1721-6.

16 Romano MA, Patel HJ, Pagani FD, Prager RL, Deeb GM, Bolling SF. Anterior leaflet repair with patch augmentation for mitral regurgitation. Ann Thorac Surg. 2005;79:1500-4.

17 Aubert S, Flecher E, Rubin S, Acar C, Gandjbakhch I. Anterior mitral leaflet augmentation with autologous pericardium. Ann Thorac Surg. 2007;83:1560-1.

18 De Bonis M, Lapenna E, La Canna G, Ficarra E, Pagliaro M, Torracca L, et al. Mitral valve repair for functional mitral regurgitation in end-stage dilated cardiomyopathy: role of the "edge-to-edge" technique. Circulation. 2005;112:I402-I408.

19 Enriquez-Sarano M, Schaff HV, Frye RL. Mitral regurgitation: what causes the leakage is fundamental to the outcome of valve repair. Circulation. 2003;108:253-6.

20 Gillinov AM, Wierup PN, Blackstone EH, Bishay ES, Cosgrove DM, White J, et al. Is repair preferable to replacement for ischemic mitral regurgitation? J Thorac Cardiovasc Surg. 2001;122:1125-41. 
21 Al-Radi OO, Austin PC, Tu JV, David TE, Yau TM. Mitral repair versus replacement for ischemic mitral regurgitation. Ann Thorac Surg. 2005;79:1260-7.

22 Bolling SF, Pagani FD, Deeb GM, Bach DS. Intermediate-term outcome of mitral reconstruction in cardiomyopathy. J Thorac Cardiovasc Surg. 1998;115:381-6.

23 Bach DS, Bolling SF. Early improvement in congestive heart failure after correction of secondary mitral regurgitation in end-stage cardiomyopathy. Am Heart J. 1995;129:1165-70.

24 Braun J, van de Veire NR, Klautz RJ, Versteegh MI, Holman ER, Westenberg JJ, et al. Restrictive mitral annuloplasty cures ischemic mitral regurgitation and heart failure. Ann Thorac Surg. 2008;85:430-6.

25 Bax JJ, Braun J, Somer ST, Klautz R, Holman ER, Versteegh MI, et al. Restrictive annuloplasty and coronary revascularization in ischemic mitral regurgitation results in reverse left ventricular remodeling. Circulation. 2004;110:II103-II108.

26 Berdat PA. Chronic ischemic mitral regurgitation: a diagnostic and therapeutic challenge. Kardiovask Med. 2007;10:271-8.

$27 \mathrm{Wu}$ AH, Aaronson KD, Bolling SF, Pagani FD, Welch K, Koelling TM. Impact of mitral valve annuloplasty on mortality risk in patients with mitral regurgitation and left ventricular systolic dysfunction. J Am Coll Cardiol. 2005;45:381-7.

28 Crabtree TD, Bailey MS, Moon MR, Munfakh N, Pasque MK, Lawton JS, et al. Recurrent mitral regurgitation and risk factors for early and late mortality after mitral valve repair for functional ischemic mitral regurgitation. Ann Thorac Surg. 2008;85:1537-42.

29 McGee EC, Gillinov AM, Blackstone EH, Rajeswaran J, Cohen G, Najam $\mathrm{F}$, et al. Recurrent mitral regurgitation after annuloplasty for functional ischemic mitral regurgitation. J Thorac Cardiovasc Surg. 2004;128:916-24.

30 Hung J, Papakostas L, Tahta SA, Hardy BG, Bollen BA, Duran CM, et al. Mechanism of recurrent ischemic mitral regurgitation after annuloplasty: continued LV remodeling as a moving target. Circulation. 2004;110:II85-II90.
31 Piechota W, Gielerak G. The prognostic value of stress tests in chronic heart failure. Cardiol J. 2007;14:340-6.

32 Mihaljevic T, Lam BK, Rajeswaran J, Takagaki M, Lauer MS, Gillinov $\mathrm{AM}$, et al. Impact of mitral valve annuloplasty combined with revascularization in patients with functional ischemic mitral regurgitation. J Am Coll Cardiol. 2007;49:2191-201.

33 Deja MA, Grayburn PA, Sun B, Rao V, She L, Krejca M, et al. Influence of mitral regurgitation repair on survival in the surgical treatment for ischemic heart failure trial. Circulation. 2012;125:2639-48.

34 Kwon MH, Cevasco M, Chen FY. Functional, ischemic mitral regurgitation: to repair or not to repair? Circulation. 2012;125:2563-5.

35 Acker MA, Bolling S, Shemin R, Kirklin J, Oh JK, Mann DL, et al. Mitral valve surgery in heart failure: insights from the Acorn Clinical Trial. J Thorac Cardiovasc Surg. 2006;132:568-77.

36 Vahanian A, Alfieri O, Andreotti F, Antunes MJ, Barón-Esquivias G, Baumgartner $\mathrm{H}$, et al. Guidelines on the management of valvular heart disease (version 2012): The Joint Task Force on the Management of Valvular Heart Disease of the European Society of Cardiology (ESC) and the European Association for Cardio-Thoracic Surgery (EACTS). Eur J Cardiothorac Surg. 2012 Aug 25. [Epub ahead of print] PubMed PMID: 22922698.

37 McMurray JJ, Adamopoulos S, Anker SD, Auricchio A, Böhm M, Dickstein K, et al. ESC Guidelines for the diagnosis and treatment of acute and chronic heart failure 2012: The Task Force for the Diagnosis and Treatment of Acute and Chronic Heart Failure 2012 of the European Society of Cardiology. Developed in collaboration with the Heart Failure Association (HFA) of the ESC. Eur Heart J. 2012 May 19. [Epub ahead of print] PubMed PMID: 22611136. 